University of Nebraska - Lincoln

DigitalCommons@University of Nebraska - Lincoln

Faculty Publications, Department of Child, Youth, and Family Studies

Child, Youth, and Family Studies, Department of

2020

\title{
Finding Strength in Vulnerability: Ethical Approaches when Conducting Research with Vulnerable Populations
}

Elizabeth Mollard

Holly Hatton-Bowers

Julie A. Tippens

Follow this and additional works at: https://digitalcommons.unl.edu/famconfacpub

Part of the Developmental Psychology Commons, Family, Life Course, and Society Commons, Other Psychology Commons, and the Other Sociology Commons

This Article is brought to you for free and open access by the Child, Youth, and Family Studies, Department of at DigitalCommons@University of Nebraska - Lincoln. It has been accepted for inclusion in Faculty Publications, Department of Child, Youth, and Family Studies by an authorized administrator of DigitalCommons@University of Nebraska - Lincoln. 


\title{
Finding Strength in Vulnerability: Ethical Approaches when Conducting Research with Vulnerable Populations
}

\author{
Elizabeth Mollard, ${ }^{1} \mathrm{CNM}, \mathrm{PhD}$ \\ Holly Hatton-Bowers, ${ }^{2} \mathrm{PhD}$ \\ Julie Tippens, ${ }^{2}$ DrPH, MA, MPH \\ 1 College of Nursing - Lincoln Division, University of Nebraska Medical Center, \\ Lincoln, Nebraska \\ 2 College of Education and Human Sciences, University of Nebraska-Lincoln, \\ Lincoln, Nebraska \\ Corresponding author - Elizabeth Mollard, email elizabeth.mollard@unmc.edu \\ ORCID \\ Elizabeth Mollard https://orcid. org/0000-0003-0221-3459 \\ Holly Hatton-Bowers https://orcid. org/0000-0002-4165-791X \\ Julie Tippens https://orcid. org/0000-0003-0465-3570
}

\begin{abstract}
:
Researchers who desire to make positive changes for vulnerable populations often conduct problem-focused studies. Although problem focused research is important, when such studies are not carefully designed, their results can contribute to a deficit discourse. A deficit discourse is a narrative that describes the person through a myopic lens of negativity characterized only by illness, death, depression, failure, or the like. Deficit discourse negatively affects how health care providers and society
\end{abstract}

Published in Journal of Midwifery \& Women's Health (2020)

doi:10. 1111/jmwh. 13151

Copyright (C) 2020 by the American College of Nurse-Midwives; published by Wiley-

Blackwell. Used by permission. 
interact with vulnerable people. This article discusses deficit discourse in health care and strengths-based research: an ethical approach to working with vulnerable individuals in research settings and a strategy to overcome deficit discourse. Strengthsbased research approaches balance risks with countermeasures that include areas that are positive and amenable to growth or intervention. Strengths-based research can be conducted using qualitative, quantitative, or mixed-methods methodology. Strengths-based research should be culturally relevant and population-specific, often including the individuals of study throughout the process. By modifying the research approach, critical problems can be identified and addressed while also emphasizing positive ways to empower individuals and improve their lives. Additionally, these changes better the way researchers and health care providers view and care for people while also challenging deficit discourses in society at large.

\section{Points}

- Vulnerable populations are often characterized by a deficit discourse, a disempowering narrative that emphasizes deficiency, risk, and failure. This discourse ignores the social and structural determinants of health and the strengths of individuals.

- Deficit discourse may negatively affect the care vulnerable persons receive from health care providers.

- Researchers should consider using strengths-based research approaches when studying persons from vulnerable populations to counter deficit discourse.

- Strengths-based research approaches can be utilized with any research methodology.

- Strengths-based research can promote interventions to examine outcomes leading to positive growth and health while also empowering persons from vulnerable populations.

\section{Introduction}

Research with human participants requires addressing several wellknown ethical considerations, such as the protection of privacy. When human research involves participants from vulnerable populations, additional ethical issues are of importance. Although there is no consensus in defining vulnerability, vulnerable populations are generally defined as groups of individuals that may be more susceptible to certain adverse outcomes. ${ }^{1}$ In health, vulnerable groups are more likely 
to experience health disparities and in research may need additional protection from risk. ${ }^{1}$ Examples of vulnerable populations include people of color; undocumented or precariously documented individuals; lesbian, gay, bisexual, transgender, and queer or questioning individuals; persons with socioeconomic disadvantage; and those with physical, cognitive, or emotional differences.

One ethical consideration related to social responsibility and respect for human dignity is the problem of deficit dis course. Deficit discourse refers to written and spoken communication about a group of people that focuses on deficiency, lack, or failure that becomes part of a normative discourse or narrative about that group. ${ }^{2-3}$ Researchers can create or promulgate a deficit discourse when conducting research with vulnerable populations.

The purpose of this article is to (1) identify the prevailing deficit discourse in health care and (2) highlight strengths-based research approaches that allow nuanced insight into how persons perceive and live with risk, overcome social and structural vulnerabilities, and experience positive growth in order to overcome deficit discourse. Although work related to vulnerable populations is presented, it should also be acknowledged that a person labeled as part of a vulnerable group does not mean that person is inherently vulnerable. 4

\section{Background}

Much of the literature about deficit discourse originates from Australia, where Indigenous people have experienced centuries of discrimination and oppression. Concurrently, a narrative has perpetuated throughout their society that portrays Indigenous citizens as having deficits or problems. Felton-Busch and Larkins ${ }^{5}$ (page 14) describe an example of deficit discourse regarding Indigenous Australian women and maternity care:

We are portrayed by the dominant discourse as perpetrating our disadvantage by the things we do (lifestyle risk factors) such as smoking, drinking and having babies young; or do not do (non-compliance) such as not attending antenatal services or attending late. We choose to live geographically remote from health services and in poverty. We do not value 
education so do not go to school and we do not maintain our houses to a healthy standard. ... Thus our Indigeneity, as informed by this "master narrative", prejudices our health.5(p. 14)

Without recognition of the deficit discourse occurring, these constructed narratives can affect the way health care providers interact with and care for people, prejudicing health care. Hoffman et al. ${ }^{6}$ studied health care practitioner trainees in the United States and found that many held misconceptions about biological differences between White and Black bodies. Beliefs such as "Black people's skin is thicker than White people's skin" led to medical decision making resulting in undertreated pain. Because much research focuses on Black patients' higher rates of chronic diseases and mortality, these future practitioners formed conceptions of fundamental and negative differences in Black bodies. The discourse, instead of group traits or characteristics, reinforced health disparities. The more interwoven and rooted the negative discourse becomes over time, the more challenging it is to identify.

In research settings, deficit discourse may originate with a researcher's well-intentioned desire to explore a significant problem occurring in a vulnerable population, such as a higher rate of morbidity and mortality. Without careful design, a research study that is problem-focused can elicit results that contribute to a deficit discourse. Although researchers may use demographic details such as race, educational status, and income to delineate aspects of a problem, the conclusions drawn from these details and the way they are disseminated can be where deficit discourse advances.

Because researchers are seen as trustworthy and often as holding objective truths, results of research can form or contribute to a deficit discourse. For example, people who have lower educational attainment are characterized as uneducated and people with lower economic status are viewed as impoverished. These individuals are then no longer considered as underserved, but rather undeserved. ${ }^{5}$ Characterizing persons from vulnerable populations in this way masks their individual experiences and obstructs ways in which they may experience positive growth. One strategy to overcome deficit discourse is through strengths-based research approaches. Strengths-based research strategies have been employed in social, education, and behavioral sciences but are not formally advocated in health-based research. 


\section{Elements and exemplars of deficit discourse in health care}

In deficit discourse, the blame for a problem is situated with the person who is experiencing it. ${ }^{3}$ Women with obese bodies seeking reproductive health care are met with a narrative of blame for their body size, the belief that they are unwilling to moderate food intake and are generally lazy. ${ }^{7}$ This deficit discourse includes the false beliefs that obese women's bodies put undue risk on their fetus, deemed motherblame. This victim-blaming orientation disregards genetics, stress related endocrine changes (such as those induced by cumulative stress from racism, sexism, or trauma), the effects of poverty and food insecurity, and access to health care, among other factors that affect obesity and are beyond one's control. Because of this blame orientation, obese women have reported being told to avoid reproducing even when their current obese bodies were otherwise healthy. ${ }^{7}$

Deficit discourse ignores the larger systems of oppression and systemic inequalities such as racism, culturalism, sexism, and socioeconomic discrimination. Many vulnerable persons have no health care coverage, and those who use government-sponsored health programs, such as Medicaid, face their own deficit discourse. Individuals reported being discriminated against in health care services when they used health coverage stigmatized as being for poor persons. ${ }^{8}$ People believed their health care was negatively affected knowing their health care provider would be given a lower payment for caring for them compared with a privately insured patient. Individuals reported feelings of shame, helplessness, and the desire to no longer interact with the health care system based on the treatment they received because of the deficit discourse related to being poor. ${ }^{8}$

Deficit discourse is pervasive and becomes an implied attribute of the individual. ${ }^{3}$ Beliefs in different, defective, and unhealthy characteristics are then reinforced when health care workers see the deficit discourse materialize without contextualization or recognition of the discourse. As an example, Black women have been perceived to not want to breastfeed; as such, health care providers are less likely to provide lactation support and are more likely to encourage the use of formula. ${ }^{9}$ Researchers often report the low occurrence of initiation and continuation of breastfeeding among these women, particularly for Black women with low incomes, without contextualizing their experiences. The narrative becomes implicit, leading to incorrect 
assumptions without addressing greater needs or why these women may not breastfeed (e.g., workplace barriers, not receiving lactation support in the hospital). ${ }^{10}$

The health care system is known for hegemony, in which the dominant view on a topic may become the only position, leaving little room for alternative ways of thinking. Health care hegemony is common in policy related to women's health and birth practices. ${ }^{3}$ For instance, Black and Hispanic women have higher rates of cesarean in the United States and less opportunity to experience labor after cesarean. ${ }^{11}$ The vaginal birth after cesarean (VBAC) calculator, a tool to help clinicians make decisions about offering labor after a cesarean, has two race-based questions that deduct points for women who are Black or Hispanic. These variables imply a deficiency in the ability to have a vaginal birth or VBAC in these populations. The evidence for race variables within this calculator is limited and disputed. ${ }^{11}$ Deficit discourse that is present within a standard tool such as the VBAC calculator (because of non-evidencebased beliefs that Black and Hispanic women have a lesser chance of VBAC) reinforces hegemonic thinking and systems. Black and Hispanic women are not given the opportunity to experience labor after cesarean because of the calculator and therefore have less opportunity for successful vaginal birth.

To avoid contributing to deficit discourse, researchers conducting health-related studies should familiarize themselves with the elements of deficit discourse in health care and ensure that they are not reinforcing these elements in their research design. Researchers must ask themselves in each stage of research, Does this tend to place blame on the participants? Is larger systemic contextualization being considered? Could the study contribute to negative pervasive and implicit beliefs about a population? Does this research reinforce negative hegemonic systems or thinking? Using strengths-based research approaches is one way researchers can lessen the burden of inadvertently contributing to a deficit discourse. 


\section{Strengths-based research approaches}

\section{Identifying Strength}

In strengths-based research, there is an intentional focus on including measures and tools that seek to understand the many strengths of vulnerable populations. Drawing upon strengths-based principles in mental health, ${ }^{12}$ a core tenant to conducting strengths-based research includes adopting an empowerment orientation that focuses on community, individual strengths, resources, meaningful relationships, and activities. Researchers may choose to use these 6 strategies in their strengths-based research approach: (1) include a focus on capabilities, strengths, and opportunities; (2) conduct research with and by instead of about the individuals or groups; (3) promote hope by using language that is person-centered and optimistic and leads to positive perceptions; (4) identify social context and the resources that exist in communities; (5) include research questions that lead to empowerment; and (6) engage research participants with respect, allowing opportunities in which they offer their own expertise about their situation.

For every measure of distress or pathology that is measured, a countermeasure of well-being should be considered. ${ }^{13}$ Researchers may focus on well-being, which encompasses elements such as quality of life, empowerment, happiness, and positivity, among others. ${ }^{4}$ Other protective strengths can be those related directly to engagement in one's health. These can include those based on self-efficacy (the belief one can succeed); patient engagement or activation (knowledge, skill, and confidence in managing health); or locus of control (how much control one feels one has over one's situation). Strengths can be found in the individual's homes, families, communities, and cultures. Sense of community, ethnic identity, and cultural beliefs are sources of strengths for individuals and should be measured and highlighted as strengths in research with vulnerable persons.

Strengths-based research is not limited to social and behavioral variables. Measuring wellness in biological or clinical variables is another strengths-based strategy. An example of seeking protective strengths in this setting was when genetic researchers studied individuals whose genes showed they should have a severe Mendelian disorder but who 
never manifested the illness. ${ }^{14}$ Studying strengths or why someone is well has the potential to mitigate deficit discourse and may lead to an innovative way to make new discoveries.

\section{Choosing a Research Method}

Quantitative, qualitative, and mixed-method research designs that include these strengths-based strategies challenge deficit discourse. Quantitative measures are critical in understanding the scope of a research question and can add credibility and, in some instances, generalizability, for key stakeholders including policy makers. ${ }^{15}$ Including survey questions that identify promotive and protective characteristics can address the issue of generalizing findings beyond a solely problem-focused lens. For example, in a recent study examining the mental well-being of resettled refugee women, surveys primarily focused on mental health problems (e.g., anxiety, depression, trauma, depression, and somatic symptoms). Although this study contributes important information about these women's mental health needs, including measures that looked at existing social supports or resiliencepromoting factors may have provided a more holistic understanding. ${ }^{16}$

The intention of identifying strengths is not to minimize the wellknown problems that stem from the disadvantages faced by vulnerable populations. Rather, the goal is to also focus on participants' capabilities, resources, and opportunities that offer a comprehensive view of vulnerable persons. Strengths-based measures are countermeasures to deficit discourse that can reframe the experiences of individuals, identify positive adaption or growth, and offer innovative discoveries for new interventions that may be more individualized and contextually appropriate. Table 1 provides examples of some strengths-based measures used in research.

Qualitative and mixed methods are important in understanding the nuance, subtlety, and depth of individuals' experiences from an emic perspective. ${ }^{17,18}$ The intentional integration of qualitative and quantitative components through mixed-methods research may increase meaning, relevancy, and understanding of the context. ${ }^{18}$ When these research approaches are used with strengths-based research principles, they provide an opportunity to include participants as experts and knowledge generators in the research process. 
Table 1. Example Measures used in Research to Identify Strengths or Protective Factors

\begin{tabular}{|c|c|c|}
\hline Measure & Measure Description & Comments \\
\hline $\begin{array}{l}\text { Wicozani Instrument: }{ }^{30} \text { measures } \\
\text { overall health and well-being } \\
\text { from Dakota perspective }\end{array}$ & $\begin{array}{l}\text { Includes } 9 \text { items and } 2 \text { subscales: } \\
\text { Wicozani Self-Knowledge } \\
\text { and Importance of Wicozani } \\
\text { to Quality of Life. Six ques- } \\
\text { tions rated on a 5-point Likert } \\
\text { scale and } 3 \text { open-ended ques- } \\
\text { tions. Internal consistency with } \\
\text { a sample of } 35 \text { Dakota women } \\
\text { (Self-Knowledge subscale, } \\
\alpha=.72 ; \text { Quality of Life sub- } \\
\text { scale, } \alpha=.98 \text { ). }\end{array}$ & $\begin{array}{l}\text { This scale serves as an example } \\
\text { of developing and using a mea- } \\
\text { sure to understand health and } \\
\text { well-being from the perspective } \\
\text { of the population being studied, } \\
\text { providing an opportunity for } \\
\text { open-ended comments. The in- } \\
\text { ternal consistency needs to be } \\
\text { determined with an adequate } \\
\text { sample size. }\end{array}$ \\
\hline $\begin{array}{l}\text { RRC-ARM (Resilience Research } \\
\text { Centre-Adult Resilience Mea- } \\
\text { sure): }{ }^{31} \text { measures resilience-en- } \\
\text { hancing resources across the } \\
\text { social ecology }\end{array}$ & $\begin{array}{l}\text { Includes } 28 \text { items, with } \alpha \text { ranging } \\
\text { from } .769 \text { to } .953 \text { across sub- } \\
\text { scales. These } 5 \text { subscales in- } \\
\text { clude family attachment and } \\
\text { supports, spirituality, personal } \\
\text { skills and competencies, iden- } \\
\text { tity, and social and community } \\
\text { inclusion. }\end{array}$ & $\begin{array}{l}\text { Demonstrated validity with adult } \\
\text { vulnerable populations. Some } \\
\text { of the subscales may be par- } \\
\text { ticularly beneficial when re- } \\
\text { searching women's health, such } \\
\text { as the role of peer supports in } \\
\text { promoting resilience. Questions } \\
\text { are positively stated and exam- } \\
\text { ine social-ecological resilience. }\end{array}$ \\
\hline Self-Compassion Scale ${ }^{32}$ & $\begin{array}{l}\text { A } 26 \text {-item scale on a 5-point scale } \\
\text { from "almost never" to "almost } \\
\text { always" measuring } 3 \text { aspects: } \\
\text { self-kindness, community hu- } \\
\text { manity, and mindfulness. } \\
\alpha=.92 \text {. }\end{array}$ & $\begin{array}{l}\text { Self-compassion has been found } \\
\text { to relate to physical and mental } \\
\text { health. There is also a 12-item } \\
\text { version available with accept- } \\
\text { able internal consistency. }\end{array}$ \\
\hline $\begin{array}{l}\text { Multigroup Ethnic Identity } \\
\text { Measure-Revised } 33\end{array}$ & $\begin{array}{l}\text { A 6-item measure rated on a } \\
\text { 5-point scale from "strongly } \\
\text { disagree" to "strongly agree," } \\
\text { providing a total score indicat- } \\
\text { ing the degree to which an in- } \\
\text { dividual identifies with their } \\
\text { ethnic group. Can also use sub- } \\
\text { scales for exploration and com- } \\
\text { mitment. Cronbach's } \alpha \text { for total } \\
\text { and subscales was approxi- } \\
\text { mately .70 or above. }\end{array}$ & $\begin{array}{l}\text { Can be used with ethnically di- } \\
\text { verse samples and was val- } \\
\text { idated with pregnant adult } \\
\text { women. }\end{array}$ \\
\hline
\end{tabular}


In focus groups and interviews, the researcher can intentionally ask strengths-based questions (e.g., "What is working well for you this moment?", "What do you think you do well?”, "What connections do you have in your community?"). Additionally, participatory approaches to research that are not bound within a certain research methodology or tied to explicit methods integrate research, education, and social action to reduce disparities. ${ }^{19}$ One compelling research approach is the use of photo voice, which is a visual research methodology using photography and other visual formats that give participants an active way to record and reflect their own and their community's concerns and strengths. Photo voice can also empower the participant to change the ways they access and use their resources. ${ }^{20}$ Although it is beyond the scope of this article to delve into each of these methodologies with great detail, examples of studies that have used strengths-based strategies in their research are presented next.

\section{Examples of Strengths-Based Research}

It is promising that many researchers working with vulnerable populations are using strengths-based, holistic approaches in their studies. For example, in a qualitative study with a racially and geographically diverse group of transgender women, researchers utilized both focus groups and individual in-depth interviews to elicit sexual health needs through a lens of overall health and well-being. ${ }^{22}$ Through this lens, participants were able to address specific sexual health needs and also identified the important strengths of connection and community utilized in overall wellness. These researchers intentionally asked questions to identify these women's strengths and resources, which can lead to meaningful solutions in supporting their sexual health needs and well-being.

Similarly, researchers identified both protective factors and risk factors associated with depressive symptoms among a sample of $73 \mathrm{fe}-$ male American Indian cancer survivors. ${ }^{23}$ Although depressive symptoms were common, social support was significantly associated with lower incidence of depressive symptoms, suggesting that instrumental and emotional support are modifiable factors to consider in health interventions for these women. 
In a quantitative study by Howell et al that examined recent and severe intimate partner violence among 112 women (70\% identified as Black), the authors intentionally included measures that assessed protective factors associated with resilience (e.g., spirituality, social support, ethnic identity, community cohesion) along with risk factors. ${ }^{24}$ This study showed that social support and spirituality were associated with more resilience, offering evidence to include these aspects in interventions to increase their cultural relevancy for Black women exposed to intimate partner violence.

As another example of using a strengths-based research approach, researchers using a mixed-methods design used qualitative narrative, visual network graphs, and quantitative social network data to study the social support networks of female sex workers and their partners. ${ }^{25}$ Although women described stigma, deportation concerns, and isolation with sex work, they also described hope and the desire to engage in risk-reducing behaviors for their children and to reunite with their families. Using both types of data gave a clearer picture of the hopes and dreams (strengths) of these participants and the barriers to achieving them.

\section{Intervention Research}

Once the strengths of a research population have been determined, it is vital to design research interventions in collaboration with the individuals from the vulnerable population. Although intervention design and implementation have a broad scope beyond this article, it is important to introduce how interventions can be utilized in a strengthsbased research trajectory.

Existing evidence-based interventions can be attempted with vulnerable persons, although the acceptability and feasibility in the population, along with the cultural relevance, should also be closely monitored. Contemplative interventions, such as Kabat-Zinn's ${ }^{26}$ mindfulness-based stress reduction and mindful self-compassion, are increasingly implemented to foster health and well-being. Although there are promising findings from this body of work, there have been limited studies examining if and how these mindfulness-based interventions are culturally responsive to African American women who may experience more stress-related disparities. To address this gap, a 
4-week version of the mindfulness-based stress reduction intervention was implemented with 7 African American women. ${ }^{27}$ Following the intervention, researchers invited participants to share their experiences and perceptions in focus groups and interviews. Although these women perceived benefits in increasing their self-efficacy, self-empowerment to deal with stressors, and their awareness of the importance of personal well-being, they also shared suggestions for increasing the intervention's cultural relevancy. These suggestions included (1) using African American facilitators, (2) having a space for storytelling to foster community connections, (3) using terms such as awareness or relaxation instead of meditation, (4) providing guided meditations in a voice that felt more culturally familiar without eliciting feelings of subjugation, and (5) providing the intervention in culturally relevant settings such as a church. Although this is a small study of one group of women, using focus groups and interviews provides another way of creating interventions that are informed by the participants using them and also ensures the use of responsible approaches to promoting health and wellness.

Adapting existing interventions for persons from vulnerable populations may be ineffective. Instead, interventions should be created with culturally grounded models of health promotion. ${ }^{28}$ For example, a talking circle was facilitated among 15 Indigenous women to learn of their perceptions of restoring balance to health using a constructivist grounded theory approach. ${ }^{29}$ These women's ideas were then used to inform the development of health-promoting interventions focused on connections to self, community, and the land. Using community-based participatory research approaches can lead to community-driven, culturally grounded interventions that result in greater improvements in health. ${ }^{19,28}$

Researchers must be careful when identifying strengths and designing interventions to avoid implying that health is based simply on some feature of character or how hard someone is trying. Instead, identifying strengths can show that protective factors or resources exist but cannot be used because of structural inequalities, or perhaps that a protective factor does not exist and that an intervention can strengthen that characteristic to aid the person in navigating a specific barrier to health. Ultimately, identifying strength when looking at risks creates a more balanced and accurate assessment of the 
individuals being studied, may reduce researcher bias, and expands opportunity for positive intervention. ${ }^{21}$

\section{Discussion}

Vulnerable populations are commonly characterized by a deficit discourse. Deficit discourse is a negative narrative and belief system constructed about a group of people focused on their perceived deficiency. Deficit discourse can situate the blame with the victim; however, the actual problems experienced by these individuals are generally symptoms of broader systemic oppression. Without recognition, the deficit discourse becomes pervasive and implicit in nature, thereby reinforcing the hegemonic systems within which the discourse was created. When possible, adding strengths-based approaches to counter deficit discourse is an ethical and essential practice when working with individuals from vulnerable populations. Researchers can measure strength whether using quantitative, qualitative, or mixed methods, as well as when using researcher-initiated or community-based participatory research designs.

Adding strengths-based approaches and recognizing deficit discourse is not a panacea to address deficit discourse; however, it is a step in the right direction. There is still the possibility that researchers and clinicians misinterpret strengths-based research as a part of the deficit discourse, such as viewing individuals who lack a strength as somehow deficient. However, strengths can be fostered and grown. Having a strength means that it can be utilized in an intervention to empower a person, whereas lacking a strength is also an area to be fostered for growth and empowerment. By conducting research with a strengths-based lens, the researcher is setting the stage to empower the individual.

Researchers should be mindful of measuring strengths, including promotive and protective factors, and considering culture and social ecology to provide a balanced and more accurate assessment while reducing researcher bias. Additionally, focusing on strengths provides a platform for meaningful intervention that is more personalized and empowering to the population of study. Interventions that are designed with and by the population of study and that include culturally relevant, feasible, and acceptable practices should be encouraged. 


\section{The Role of Midwifery in Overcoming Deficit Discourse}

Midwives are well situated to counter deficit discourse in both research and clinical practice. Midwives have been vital to overcoming inequality in health and health systems. The midwifery model of care, built upon wellness and partnering with and empowering persons, is a natural platform for conducting strengths-based research in vulnerable populations. Midwifery's focus on individualized, equitable, and ethical care focused on the dignity of each person situates midwives as leaders in overcoming deficit discourses in research and society.

\section{Conclusion}

Researchers must maintain the highest standards of ethics when working with human participants. When a researcher is working with individuals from vulnerable populations, there is an additional ethical consideration to avoid the development or promulgation of a deficit discourse. Deficit discourse must be challenged from all areas of society, but most especially from those who interact with and disseminate information about vulnerable populations. Adopting strengths-based approaches in research can create positive changes in how researchers work with vulnerable populations and make a difference to overcome deficit discourses.

Conflict of Interest - The authors have no conflicts of interest to disclose.

\section{References}

1. Bracken-Roche D, Bell E, Macdonald ME, Racine E. The concept of 'vulnerability' in research ethics: an in-depth analysis of policies and guidelines. Health Res Policy Syst. 2017;15(1):8.

2. Fogarty W, Lovell M, Langenberg J, Heron MJ. Deficit Discourse and StrengthsBased Approaches: Changing the Narrative of Aboriginal and Torres Strait Islander Health and Wellbeing. Acton, Australia: National Centre for Indigenous Studies, Australian National University; Acton, Australia: Lowitja Institute; 2018. 
3. Patton Davis L, Museus SD. What is deficit thinking? An analysis of conceptualizations of deficit thinking and implications for scholarly research. Currents. 2019;1(1):117-130.

4. De Chesnay M, Anderson BA, eds. Caring for the Vulnerable: Perspectives in Nursing Theory, Practice, and Research. 5th ed. Burlington, MA: Jones \& Bartlett Learning; 2020.

5. Felton-Busch C, Larkins S. Remote dwelling Aboriginal Australian women and birthing: a critical review of literature. Women Birth. 2019;32(1):6-15.

6. Hoffman KM, Trawalter S, Axt JR, Oliver MN. Racial bias in pain assessment and treatment recommendations, and false beliefs about biological differences between blacks and whites. Proc Natl Acad Sci U S A. 2016;113(16):4296-4301.

7. Bombak AE, McPhail D, Ward P. Reproducing stigma: interpreting "overweight" and "obese" women's experiences of weight-based discrimination in reproductive health care. Soc Sci Med. 2016;166:94-101.

8. Isbell JK, Baker JC, Zagumny L, Spears A, Camuti A. Maintaining the myth: how Tennessee perpetuates deficit thinking about recipients of governmentsponsored health care. J Poverty. 2018;22(1):23-41.

9. Gross TT, Powell R, Anderson AK, Hall J, Davis M, Hilyard K. WIC peer counselors' perceptions of breastfeeding in African American women with lower incomes. J Hum Lact. 2015;31(1):99-110.

10. Robinson K, Fial A, Hanson L. Racism, bias, and discrimination as modifiable barriers to breastfeeding for African American women: a scoping review of the literature. J Midwifery Womens Health. 2019;64(6):734-742.

11. Vyas DA, Jones DS, Meadows AR, Diouf K, Nour NM, Schantz-Dunn J. Challenging the use of race in the vaginal birth after cesarean section calculator. Womens Health Issues. 2019;29(3):201-204.

12. Pulla V, Francis AP. A strengths approach to mental health. In: Francis AP, ed. Social Work in Mental Health: Contexts and Theories for Practice. Thousand Oaks, CA: SAGE Publications; 2014:126-143.

13. Howell KH, Coffey JK, Fosco GM, et al. Seven reasons to invest in well-being. Psychol Violence. 2016;6(1):8-14.

14. Chen R, Shi L, Hakenberg J, et al. Analysis of 589,306 genomes identifies individuals resilient to severe Mendelian childhood diseases. Nature Biotechnol. 2016;34(5):531-538.

15. Morse JM. Quantitative Health Research. Thousand Oaks, CA: SAGE Publications; 1992.

16. Schweitzer RD, Vromans L, Brough M, et al. Recently resettled refugee women-at-risk in Australia evidence high levels of psychiatric symptoms: individual, trauma and post-migration factors predict outcomes. BMC Med. 2018;16(1):149.

17. Patton MQ. Qualitative Research \& Evaluation Methods: Integrating Theory and Practice. 4th ed. Thousand Oaks, CA: SAGE Publications; 2014.

18. Creswell JW, Clark VLP. Designing and Conducting Mixed Methods Research. 3rd ed. Thousand Oaks, CA: SAGE Publications; 2017. 
19. Wallerstein NB, Duran B. Using community-based participatory research to address health disparities. Health Promot Pract. 2006;7(3):312-323.

20. Budig K, Diez J, Conde P, Sastre M, Hernán M, Franco M. Photovoice and empowerment: evaluating the transformative potential of a participatory action research project. BMC Public Health. 2018;18(1):432.

21. Cording JR, Christofferson SMB. Theoretical and practical issues for the measurement of protective factors. Aggress Violent Behav. 2017;32:45-54.

22. Sun CJ, Anderson KM, Mayer L, Kuhn T, Klein CH. Findings from formative research to develop a strength-based HIV prevention and sexual health promotion mHealth intervention for transgender women. Transgend Health. 2019;4(1):350-358.

23. Roh S, Burnette CE, Lee YS, et al. Identifying risk and protective factors related to depressive symptoms among Northern Plains American Indian women cancer survivors. Women Health. 2019;59(6):646-659.

24. Howell KH, Thurston IB, Schwartz LE, Jamison LE, Hasselle AJ. Protective factors associated with resilience in women exposed to intimate partner violence. Psychol Violence. 2018;8(4):438-447.

25. Wagner KD, Syvertsen JL, Verdugo SR, Molina JL, Strathdee SA. A mixed methods study of the social support networks of female sex workers and their primary noncommercial male partners in Tijuana, Mexico. J Mix Methods Res. 2018;12(4):437-457.

26. Kabat-Zinn J. Mindfulness-based interventions in context: past, present, and future. Clin Psychol (New York). 2003;10(2):144-156.

27. Watson-Singleton NN, Black AR, Spivey BN. Recommendations for a culturally-responsive mindfulness-based intervention for African Americans. Complement Ther Clin Pract. 2019;34:132-138.

28. Walters KL, Johnson-Jennings M, Stroud S, et al. Growing from our roots: strategies for developing culturally grounded health promotion interventions in American Indian, Alaska Native, and Native Hawaiian communities. Prev Sci. 2020;21 (suppl 1):54-64.

29. Gesink D, Whiskeyjack L, Guimond T. Perspectives on restoring health shared by Cree women, Alberta, Canada. Health Promot Int. 2019;34(3):454-461.

30. Peters HJ, Peterson TR; Dakota Wicohan Community. Developing an Indigenous measure of overall health and well-being: the Wicozani Instrument. Am Indian Alask Native Ment Health Res. 2019;26(2):96-122.

31. Liebenberg L, Moore JC. A social ecological measure of resilience for adults: the RRC-ARM. Soc Indic Res. 2018;136(1):1-19.

32. Neff KD. The development and validation of a scale to measure selfcompassion. Self Identity. 2003;2(3):223-250.

33. Phinney JS, Ong AD. Conceptualization and measurement of ethnic identity: current status and future directions. J Couns Psychol. 2007;54(3):271-281. 